\title{
Flame Extinction and Re-Ignition in a Swirl Stabilized Prevaporized Liquid Fuel Flame Close to Lean Blow-Out
}

\author{
Christoph M. Arndt ${ }^{1, *}$, Adam M. Steinberg ${ }^{2, \dagger, 8}$, Wolfgang Meier ${ }^{3, *}$ \\ *German Aerospace Center (DLR), Institute of Combustion Technology, Stuttgart, Germany \\ 'University of Toronto, Institute for Aerospace Studies, Toronto, Canada \\ ${ }^{\S}$ Present Address: Georgia Institute of Technology, Daniel Guggenheim School of Aerospace Engineering, \\ Atlanta, GA, USA
}

\begin{abstract}
The dynamics of a dual-swirl gas turbine model combustor (GTMC) at atmospheric pressure close to lean low-out (LBO) are studied using laser diagnostic and optical measurements with high spatio-temporal resolution. When operated close to the LBO, the GTMC exhibits an intermittent state, and frequently partial or global extinction of the flame followed by a re-ignition of the flame are observed. In the present study, the GTMC was operated using prevaporized ethanol as fuel. Both air and fuel as well as all supply lines were preheated to $100^{\circ} \mathrm{C}$ in order to avoid any fuel condensation within the supply lines or inside the fuel plenum. The flow field was measured with stereoscopic particle image velocimetry (S-PIV), the distribution of the $\mathrm{OH}$ radical within the combustion chamber was measured using planar laser-induced fluorescence (OH PLIF) and the overall flame shape and flame dynamics was imaged using $\mathrm{OH}^{*}$ chemiluminescence $\left(\mathrm{OH}^{*} \mathrm{CL}\right)$. All optical and laser-based measurements performed at a sustained repetition rate of $10 \mathrm{kHz}$. The time scales of the flame extinction and re-ignition as well as the frequency of the extinction events were deduced from time series of the integrated $\mathrm{OH}^{*} \mathrm{CL}$ signal. Conditionally averaged flow fields of the reacting and extinguished state were used to derive information about the reignition process, which is discussed using time series of OH PLIF and OH* CL.
\end{abstract}

\section{Nomenclature}

$L \quad=$ air split ratio

$\dot{m} \quad=$ mass flow

$P_{t h} \quad=$ thermal power

$\varphi \quad=$ equivalence ratio

$\xi=$ mixture fraction

$\mathrm{CL} \quad=$ Chemiluminescence

GT $=$ gas turbine

GTMC = gas turbine model combustor

IRZ = inner recirculation zone

ISL $\quad=$ inner shear layer

LBO = Lean Blow-Out

ORZ = outer recirculation zone

PSD $\quad=$ Power Spectral Density

$\mathrm{PVC}=$ precessing vortex core

PLIF = Planar Laser-Induced Fluorescence

S-PIV = Stereoscopic Particle Image Velocimetry

\footnotetext{
${ }^{1}$ Research Associate, Combustion Diagnostics Department, christoph.arndt@dlr.de

${ }^{2}$ Associate Professor, Senior Member AIAA

${ }^{3}$ Department Head, Combustion Diagnostics Department
} 
$\begin{array}{ll}\mathrm{dt} & =\text { pulse separation time } \\ ()_{\mathrm{i}} & =\text { inner } \\ ()_{\mathrm{o}} & =\text { outer } \\ ()_{\mathrm{r}} & =\text { reacting } \\ ()_{\mathrm{nr}} & =\text { non-reacting }\end{array}$

\section{Introduction}

A lternative aviation fuels are becoming of increased importance due to the commitment of the airline industry to achieve $\mathrm{CO}_{2}$ neutral growth from 2020 onwards [1], and due to the finite sources of crude oil based kerosene. Those fuels can be produced from a variety of sources, such as coal, natural gas, biomass or as power-based fuels (often termed "e-fuels"). The corresponding production pathways offer control of the chemical composition of the fuel, allowing the optimization of the physical, chemical and combustion properties. Depending on the feedstock and process parameters, alternative fuels can contain hydrocarbons of significantly different types and chain lengths [2]. For a detailed understanding of the combustion behavior of different fuels, knowledge of the combustion properties of the single fuel components is of great importance [3-5]. However, the influence of the chemical composition of the fuel on combustion performance is not fully understood [6].

In technical applications, the combustion of liquid fuels is governed by four main processes: atomization, vaporization, turbulent mixing and chemical reaction. These processes occur simultaneously, have strong interactions and cannot easily be distinguished. Here, prevaporized liquid fuels have the potential to separate physical and chemical processes, allowing studying the combustion properties of different fuels based on their chemical properties alone. One important aspect is the lean blow-out (LBO) limit of different fuels [7-9] and hence also the dynamics of the lean blow-out process [10-12]. Since this process is highly dynamic and occurs on timescales on the order of milliseconds, optical diagnostics with high spatio-temporal resolution are necessary in order to fully resolve this phenomenon.

In recent years, different approaches for online prediction of the LBO were discussed, for example based on chemiluminescence sensors [13, 14] or sensors in combination with a chemical reactor network [15]. However, prediction of the lean blow-out limit during the design process or for different fuels remains challenging. Thus, the LBO has to be determined experimentally. Here, the LBO limit can depend on different parameters, such as the swirl number or the sense of a secondary swirl [16-18]. The LBO is also dependent on the reactivity of the flow, and can be influenced by the injection of pilot fuel/air [19], or by the preheat temperature [16].

In the current study, a gas turbine model combustor (GTMC) was adapted and set-up for the study of prevaporized single component fuels [20]. Prevaporized ethanol was supplied to the combustor using a direct evaporizer. All supply lines and the combustion air were preheated to $100^{\circ} \mathrm{C}$ in order to avoid fuel condensation within the supply lines. Laser-based and optical diagnostics with high spatio-temporal resolution, namely stereoscopic particle image velocimetry (S-PIV), $\mathrm{OH}$ planar laser-induced fluorescence (OH PLIF) and $\mathrm{OH}^{*}$ chemiluminescence (OH* $\mathrm{CL}$ ) were applied at a sustained repetition rate of $10 \mathrm{kHz}$ to measure the flow-field and flame dynamics close to the lean blow-out limit. Additionally, pressure fluctuations within the air plenums and within the combustion chamber were measured using calibrated microphone probes. Close to the LBO, the flame exhibited an intermittent state, where it frequently partial or global extinction, followed by a re-ignition of the flame was observed. The goal of the current study is to study the flame dynamics close to the LBO limit and to identify the cause-and-effect chain of the flame extinction and re-ignition. 


\section{Experimental}

\section{A. SFB Dual Swirl Burner}

A schematic of the combustor can be seen in Figure 1. Details on the geometry can be found in the literature [21-23], and only a brief overview is provided here. The design is based on previously studied dual-swirl-burner configurations, but features several improvements to the boundary conditions. Most importantly, the burner features two swirlers with separate plenum chambers. Thus, the air flow to each plenum can be controlled independently, such that the air split ratio between the inner and outer nozzle can be set exactly. The combustion chamber offers very good optical access and it is equipped with several ports for pressure probes. A nearly identical setup is available for liquid fuels [24]. Further, the design allows for several identical burners to be combined into a combustor array, in order to investigate cross-flame interactions [25]. Previous studies have focused on the feedback mechanism of the thermo-acoustic cycle [21], the variations of the thermo-chemical state throughout the acoustic cycle [22], the influence of the air split ratio on the dynamics of a precessing vortex core (PVC) [23] and the impact of the material temperature on thermo-acoustic properties of the burner [26].

In the current experiments, the combustion dynamics of prevaporized liquid fuel flames (here: ethanol) were studied using high speed laser diagnostics. An overview of the operating conditions studied in this paper is shown in Table 1.

\begin{tabular}{cccccc}
\hline $\begin{array}{c}L \\
{[-]}\end{array}$ & $\begin{array}{c}\dot{m}_{\text {air }, i} \\
{[\mathrm{~g} / \mathrm{min}]}\end{array}$ & $\begin{array}{c}\dot{m}_{\text {air }, o} \\
{[\mathrm{~g} / \mathrm{min}]}\end{array}$ & $\begin{array}{c}\dot{m}_{\text {air }, C_{2} \mathrm{H}_{6} O} \\
{[\mathrm{~g} / \mathrm{min}]}\end{array}$ & $\begin{array}{c}\mathrm{P}_{\text {th }} \\
{[\mathrm{kW}]}\end{array}$ & $\begin{array}{c}\varphi_{\text {global }} \\
{[-]}\end{array}$ \\
\hline 1.6 & 154 & 246 & 1.09 & 8.1 & 0.41 \\
\hline \multicolumn{7}{c}{ Table 1. Operating Conditions. }
\end{tabular}

Fuel was supplied to a direct evaporizer (aSteam DV1) using a mass flow controller (Bronkhorst Mini Coriflow) fed by a piston accumulator, which was pressurized using nitrogen. All fuel lines were heated to a temperature of $\mathrm{T}_{\text {fuel }}=150^{\circ} \mathrm{C}$ to avoid condensation in the fuel supply. Additionally, the air was preheated to $\mathrm{T}_{\text {air }}=100^{\circ} \mathrm{C}$ using two electrical air heaters (Osram Sylvania Threaded Inline) to avoid condensation in the nozzle. The air and fuel temperatures were monitored using thermocouples close to the air swirlers and inside the fuel plenum, respectively.

\section{B. High-Speed OH Planar Laser-Induced Fluorescence (HS OH PLIF)}

A schematic of the experimental setup is shown in Figure 2. $\mathrm{OH}$ planar laser-induced fluorescence was measured at a repetition rate of $10 \mathrm{kHz}$ using a Sirah Credo Dye laser pumped by an Edgewave DPSS pump laser. The frequency doubled output of the dye laser was tuned around $283.2 \mathrm{~nm}$ to match the $\mathrm{Q}_{1}(7)$ transition of $\mathrm{OH}$ in the $(\mathrm{A}-\mathrm{X}) 1,0$ band. The laser beam was extended into a light sheet using a two-stage cylindrical telescope and focused into the 
test section using a third cylindrical telescope, resulting in a laser sheet of approximately $45 \mathrm{~mm}$ height with a $0.4 \mathrm{~mm}$ beam waist. The fluorescence signal in the $(1,1)$ and $(1,0)$ band was collected using a high speed CMOS camera (Photron SA5) equipped with a two-stage high speed image intensifier (LaVision HS IRO), a Halle $f=64 \mathrm{~mm} \mathrm{f} / 2 \mathrm{UV}$ lens and a high transmission $(\mathrm{T}>80 \%$ at $310 \mathrm{~nm})$ band pass filter. A part of the light sheet was coupled into a dye cell containing Rhodamine $6 \mathrm{G}$ solved in ethanol to correct for shot-to-shot sheet profile and laser energy fluctuations. Fluorescence from the dye cell was imaged using a Photron SA1.1 high-speed CMOS camera equipped with a Nikon Nikkor $f=50 \mathrm{~mm}$ f/1.4 lens.

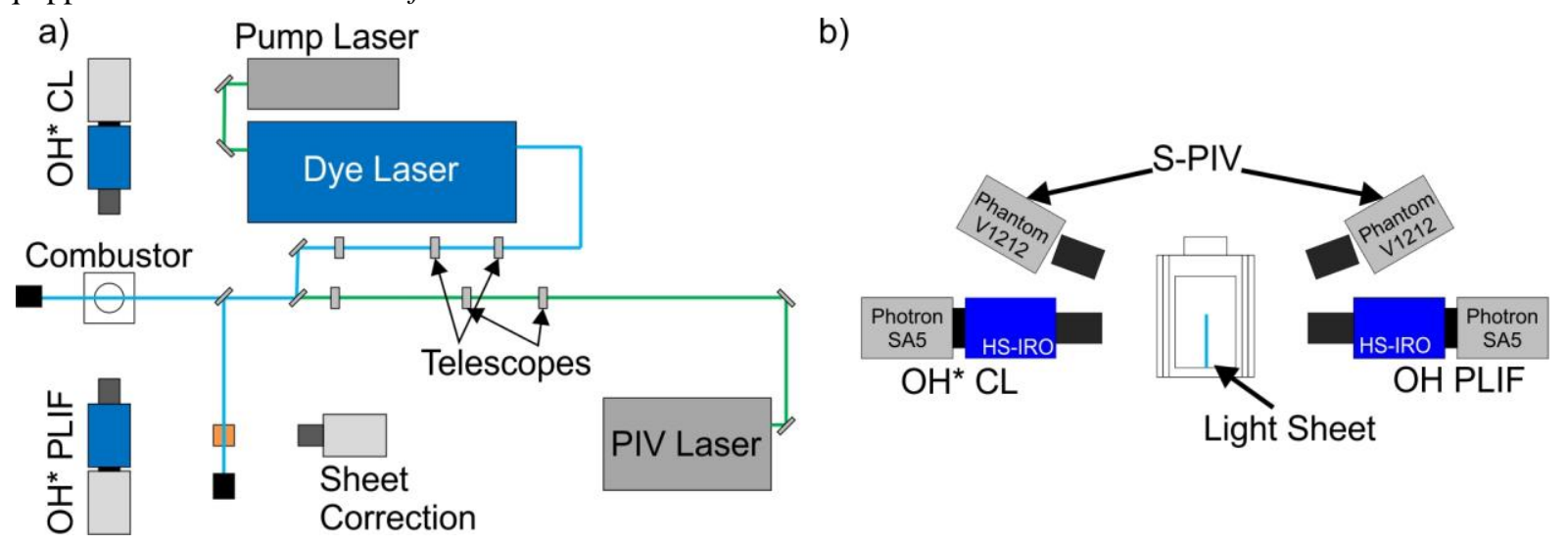

Figure 2. Experimental Setup. a) top view b) front view.

\section{High Speed Stereoscopic Particle Image Velocimetry (HS S-PIV)}

The three-component velocity field in the measurement plane was acquired with Stereoscopic Particle Image Velocimetry (S-PIV) at a repetition rate of $10 \mathrm{kHz}$. Titanium dioxide $\left(\mathrm{TiO}_{2}\right)$ particles were added to the flow and illuminated with a frequency doubled dual-head Nd:YAG laser (Edgewave) with a pulse energy of $5 \mathrm{~mJ}$ at $532 \mathrm{~nm}$ and a pulse separation time of $20 \mu \mathrm{s}$. Mie scattering of the particles was recorded with a pair of high speed CMOS cameras (Phantom V1212). The cameras were mounted at an angle of $30^{\circ}$ relative to the normal of the laser light sheet and equipped with Tokina $f=100 \mathrm{~mm}$ macro lenses (set to $\mathrm{f} / 5.6)$ and band-pass filters $(532 \pm 5 \mathrm{~nm}$ ) to suppress background luminosity of the flame. A total of 30.000 single shot particle pairs were recorded for each operating condition and the velocity fields were calculated from the particle image pairs using a multi-scale cross-correlation PIV algorithm (LaVision DaVis 8.3).

\section{OH* Chemiluminescence $(\mathrm{CL})$}

$\mathrm{OH}^{*}$ chemiluminescence was measured simultaneously with the OH PLIF and S-PIV measurements using a Photron SA5 high speed CMOS camera equipped with a LaVision HS IRO image intensifier. The intensifier was equipped with a Cerco $f=45 \mathrm{~mm}$ f/1.8 UV lens and a bandpass filter centered around $310 \mathrm{~nm}$ to collect $\mathrm{OH}^{*}$ chemiluminescence in the $(1,0)$ and $(1,1)$ band.

\section{E. Acoustic Measurements}

Pressure oscillations in the combustion chamber and in the two air plenums were measured using calibrated microphone probes (Brüel \& Kjær, type 4939), with a sampling rate of $100 \mathrm{kHz}$. The microphone probes were calibrated for frequencies up to $10.000 \mathrm{~Hz}$. The pressure power spectrum at each location was computed by slicing the long-duration pressure signal into one-second segments, and calculating the power spectrum for each segment. Afterwards, the spectra of the segments were averaged, resulting in a frequency resolution of $1 \mathrm{~Hz}$. No additional filtering or smoothing of the raw signals or the frequency spectra was performed. Acoustic modes leading to an asymmetric pressure distribution in the combustion chamber, such as transversal thermo-acoustic modes or asymmetric flow instabilities like precessing vortex cores (PVCs) could be detected by calculating the frequency spectrum of the difference signal of two microphone probes that were mounted on opposite sides of the combustion chamber, but at the same axial position. 


\section{Results and Discussion}

Close to the lean blow-out (LBO) limit, the flame exhibits a intermittent state, where it frequently lifts off and becomes partially or globally extinguished. After a short time span of a few hundred microseconds, the flame reignites and a "stable" flame is re-established. First, a brief overview of the flame during the stable state is given. Figure 3 shows the mean $\mathrm{OH}^{*} \mathrm{CL}$ signal (on the left-hand-side) and the standard deviation (on the right-hand-side) of the $\mathrm{OH}^{*} \mathrm{CL}$ signal.

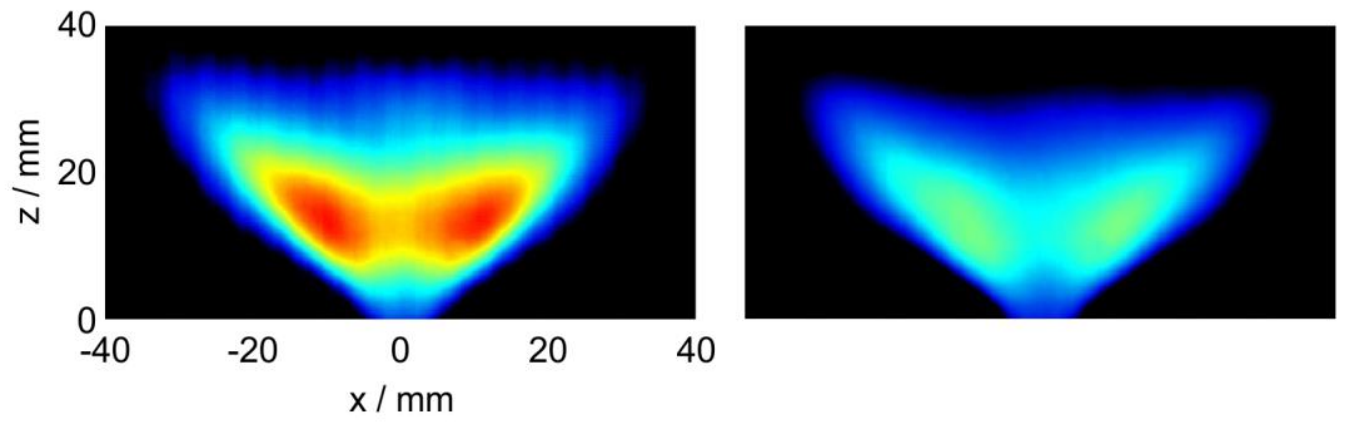

Figure 3. Mean (left) and standard deviation (right) of the $\mathrm{OH}^{*}$ chemiluminescence signal.

The flame exhibits a V-shape and is attached to the nozzle, the main flame zone is approximately $15 \mathrm{~mm}$ downstream of the fuel nozzle, the flame brush extends downstream to $\mathrm{z}=35 \mathrm{~mm}$. The main zones of the heat release fluctuations are in the inner shear layer between the inflow and the recirculation zone. In contrast to methane flames in the same combustor (without preheated air) [23], where the flame brush extends throughout the complete combustion chamber when approaching the LBO, for prevaporized ethanol (with preheated air), the flame becomes more compact with decreasing equivalence ratio until it extinguishes completely.

Figure 4 shows the mean flow field during the stable state (left) and when the flame is extinct (right).
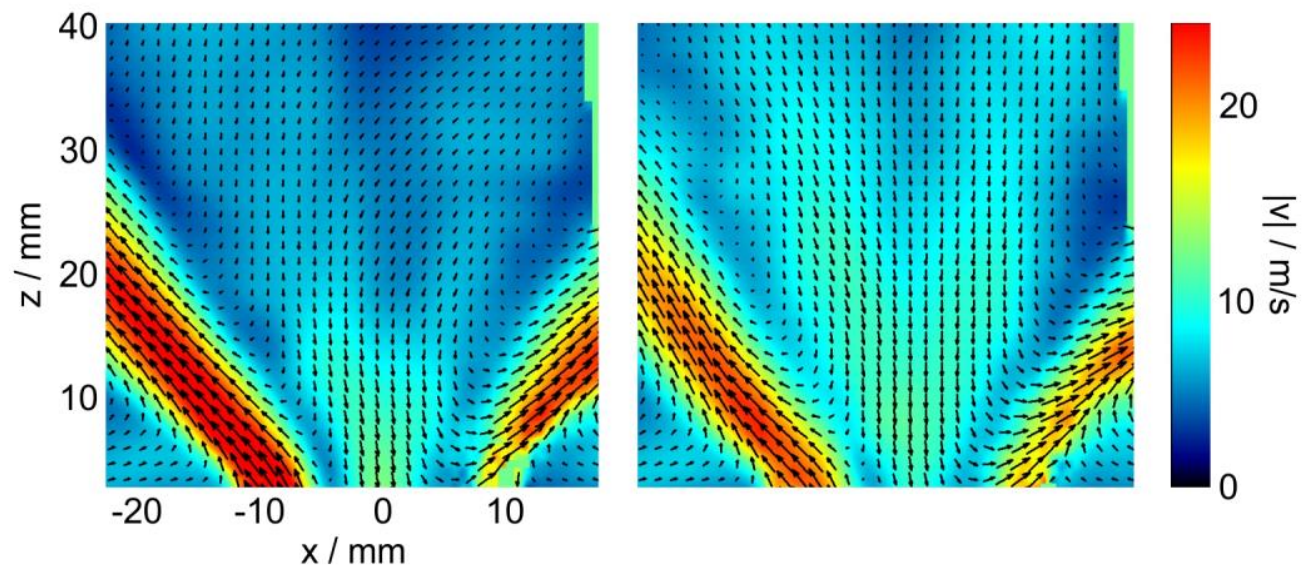

Figure 4. Mean flow field of the reacting (left) and extinguished (right) state. Color coded is the total velocity and overlaid are the velocity arrows.

Both flow fields are typical for enclosed swirl flows, featuring a high velocity inflow region and an inner (IRZ) and outer recirculation zone (ORZ). The shape of the flow field is similar for both the reacting and the extinct state with a similar apex of the inflow for both flows. However, the velocity magnitudes of the flow fields differ significantly. While the reacting state features higher inflow velocities with an axial velocity component of approximately $u_{\mathrm{ax}, \mathrm{r}}=20 \mathrm{~m} / \mathrm{s}$ (at $\mathrm{z}=2.5 \mathrm{~mm}$ ), the axial velocity component of the extinct state at the same location is on the order of $u_{\mathrm{ax}, \mathrm{nr}}=15 \mathrm{~m} / \mathrm{s}$. In contrast, the backflow in the extinct state is more pronounced with a larger region of high negative axial velocities (up to $u_{\mathrm{ax}, \mathrm{nr}}=-10 \mathrm{~m} / \mathrm{s}$ ). This larger and more pronounced region of negative axial velocities could play an important role in the re-ignition process, as will be discussed below.

As mentioned above, the flame frequently extinguishes, and, after a short time span of $20 \mathrm{~ms}$ to $50 \mathrm{~ms}$, the flame re-ignites, and subsequently a "stable" flame establishes. This sequence of events repeats every $100 \mathrm{~ms}$ to $200 \mathrm{~ms}$. Hence, during the recording sequence of $3 \mathrm{~s}$, approximately 5 global and approximately 10 local extinction events 
were observed. A similar behavior was also observed e.g. in gas-fueled GTMCs [10], in pre-vaporized fuel flames [27], and in spray flames [28].

The process and dynamics of the extinction and re-ignition process are shown in Figure 5.
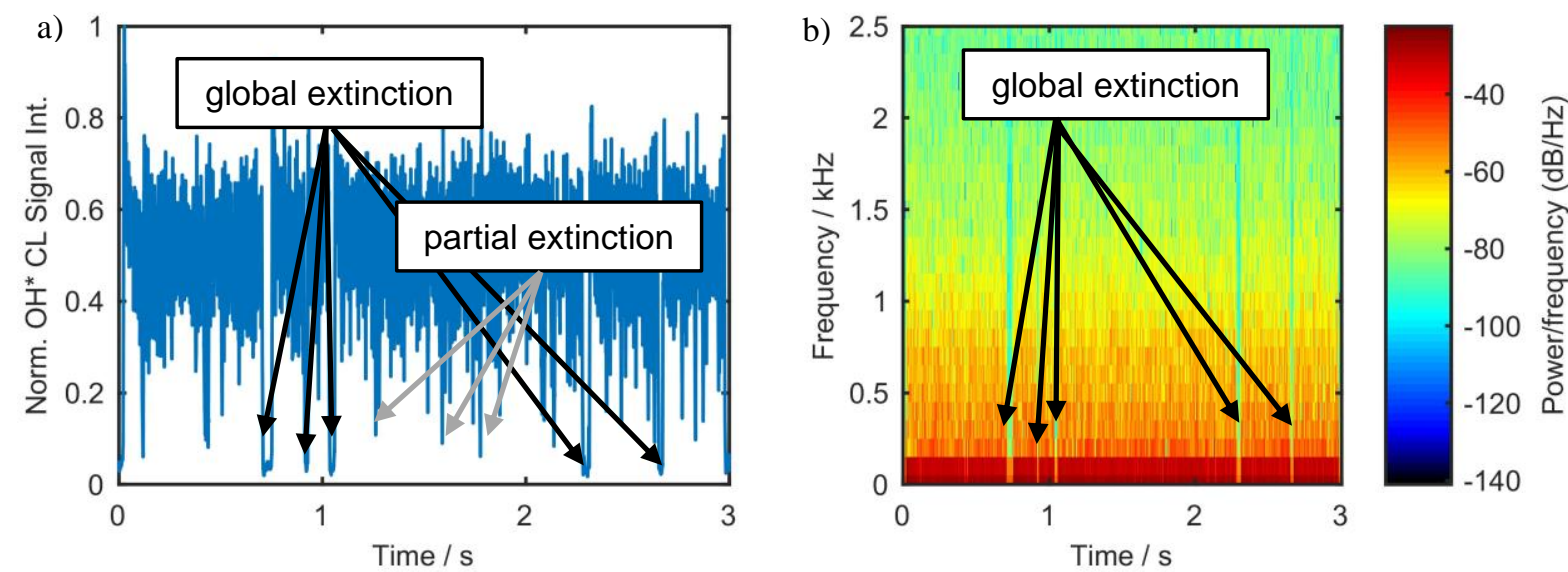

Figure 5. a) Time trace of the average $\mathrm{OH}^{*} \mathrm{CL}$ signal. b) Spectrogram of the average $\mathrm{OH} * \mathrm{CL}$ signal. Global and local extinction events are labeled using black and grey arrows, respectively.

In Figure 5 a) a time trace of the normalized average $\mathrm{OH}^{*} \mathrm{CL}$ signal is shown. Frequently, a steep "dip" in the signal intensity is observed (marked by the black and grey arrows in Figure 5 a)). Those dips can correspond to global extinction events (signal level $<0.1$, marked by the black arrows), where the flame is extinct completely and is later re-ignited by an ignition event, as will be discussed below. Additionally, partial extinction events are observed (signal level $<0.25$, marked by the grey arrows), where large regions of the flame become extinct for a short period of time. However, in the latter case, a part of the flame persists, such that after a short time span, a stable flame is re-established. During the $3 \mathrm{~s}$ recording sequence, the flame is extinct (defined as an $\mathrm{OH} * \mathrm{CL}$ signal level $<0.1$ ) for approximately $5 \%$ of the time and partially extinct (defined as an $\mathrm{OH}^{*} \mathrm{CL}$ signal level $<0.25$ and $>0.1$ ) for approximately $1.9 \%$ of the time. Figure $5 \mathrm{~b}$ ) shows a spectrogram of the average $\mathrm{OH}^{*} \mathrm{CL}$ signal. No dominant frequency is observed for global fluctuations, however the global extinction events can be observed as regions in the spectrogram where the PSD is very low for all examined frequencies (marked by the black arrows). The partial extinction events are not visible in the spectrogram.

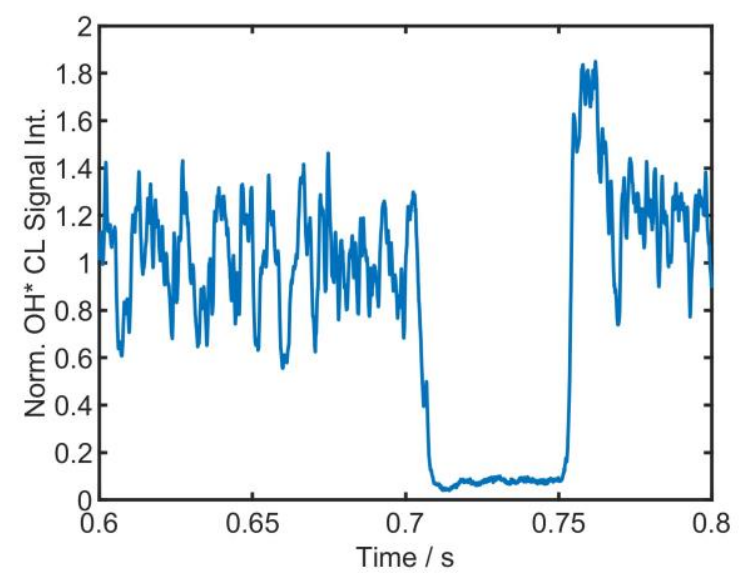

Figure 6. Zoom in on the time trace of the $\mathrm{OH}^{*} \mathrm{CL}$ signal during a global extinction and re-ignition event.

Figure 6 shows the time trace of the $\mathrm{OH}^{*} \mathrm{CL}$ signal during a global extinction event. Before the extinction event, the $\mathrm{OH}^{*}$ signal intensity fluctuates around its long-time mean value with a standard deviation of approximately $25 \%$. At $\mathrm{t}=0.7 \mathrm{~s}$, a fast decrease of the CL signal intensity occurs, which lasts for approximately $10 \mathrm{~ms}$, until a signal level close to zero is reached, corresponding to a global extinction event. The signal intensity remains $<0.1$ (corresponding to image noise) for approximately $40 \mathrm{~ms}$, followed by a fast increase of the signal level for $5 \mathrm{~ms}$, 
corresponding to a re-ignition event. Hence, the duration of the re-ignition event is approximately half as long as the duration of the extinction event. Subsequently, the signal level increases to nearly twice the long-time mean value. This is due to unburnt fuel that accumulated in the combustion chamber during the flame extinction being rapidly consumed. After a $10 \mathrm{~ms}$ period of strongly increased fuel consumption and $\mathrm{OH}^{*} \mathrm{CL}$ signal intensity, the flame reaches a mean value approximately $20 \%$ higher than the long-time mean value, probably also due to unburnt fuel in the combustion chamber being consumed. The long-time mean value is reached approximately $250 \mathrm{~ms}$ later.

An overview of the flame dynamics during the extinction process is shown in Figure 7.
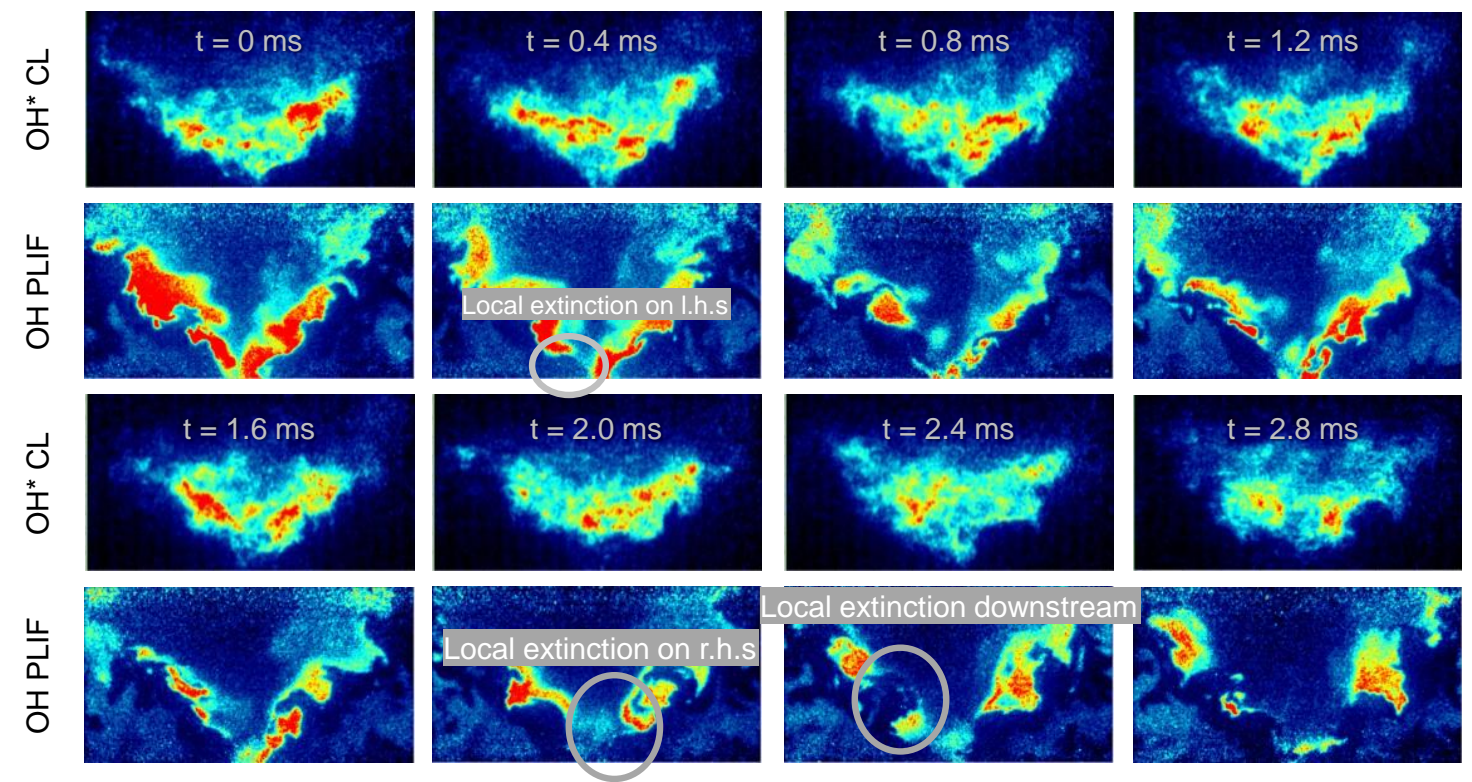

Figure 7. Image sequence of $\mathrm{OH}^{*}$ chemiluminescence and $\mathrm{OH}$ PLIF during the flame lift-off in an intermittent state close to the lean blow-out limit. For a better overview, only every fourth image frame is shown, corresponding to a time between the images of $0.4 \mathrm{~ms}$.

Here, a time sequence of $\mathrm{OH}^{*}$ chemiluminescence and OH PLIF is shown. The time between frames of $0.4 \mathrm{~ms}$, corresponding to every fourth frame in the image sequence. As visible from the OH PLIF measurement, the flame stabilizes within the inner air nozzle, i.e. the flame root is upstream of the burner exit plane. For the operation with gaseous fuels (and without preheating the air) [21], as well as in similar geometries [10], the flame root was found to be several millimeters downstream of the burner exit plane. As $\mathrm{OH}^{*} \mathrm{CL}$ is a line-of-sight integrated measurement technique, it is well suited to determine "global" parameters of the flame, such as a lift-off of the flame, or global extinction. OH PLIF on the other hand is a 2D-light sheet technique which is more suited to determine cause-andeffect chains in dynamic flame processes due to the higher spatial resolution. At $\mathrm{t}=0.4 \mathrm{~ms}$, a first local extinction event can be observed in the OH PLIF image on the left-hand-side of the flame root. The extinct flame region subsequently growths in size and is transported downstream. At $\mathrm{t}=1.2 \mathrm{~ms}$, the extinction event is partially mended, either due to flame propagation, or due to transport of a flame fragment from outside the measurement plane. At $\mathrm{t}=2.0 \mathrm{~ms}$, an additional extinction event at the flame root can be observed on the r.h.s. of the flame. Shortly after that, a large extinction event is observed further downstream of the fuel nozzle on the left hand side. At $\mathrm{t}=2.8 \mathrm{~ms}$, large regions of the flame are extinct, and shortly after (not shown in the image sequence), the flame is globally extinct. Only after extinction of the flame downstream of the burner exit plane, the flame appears to be lifted from the burner nozzle for a short period of time until it extinguishes completely. 
The following re-ignition event is shown in Figure 8.
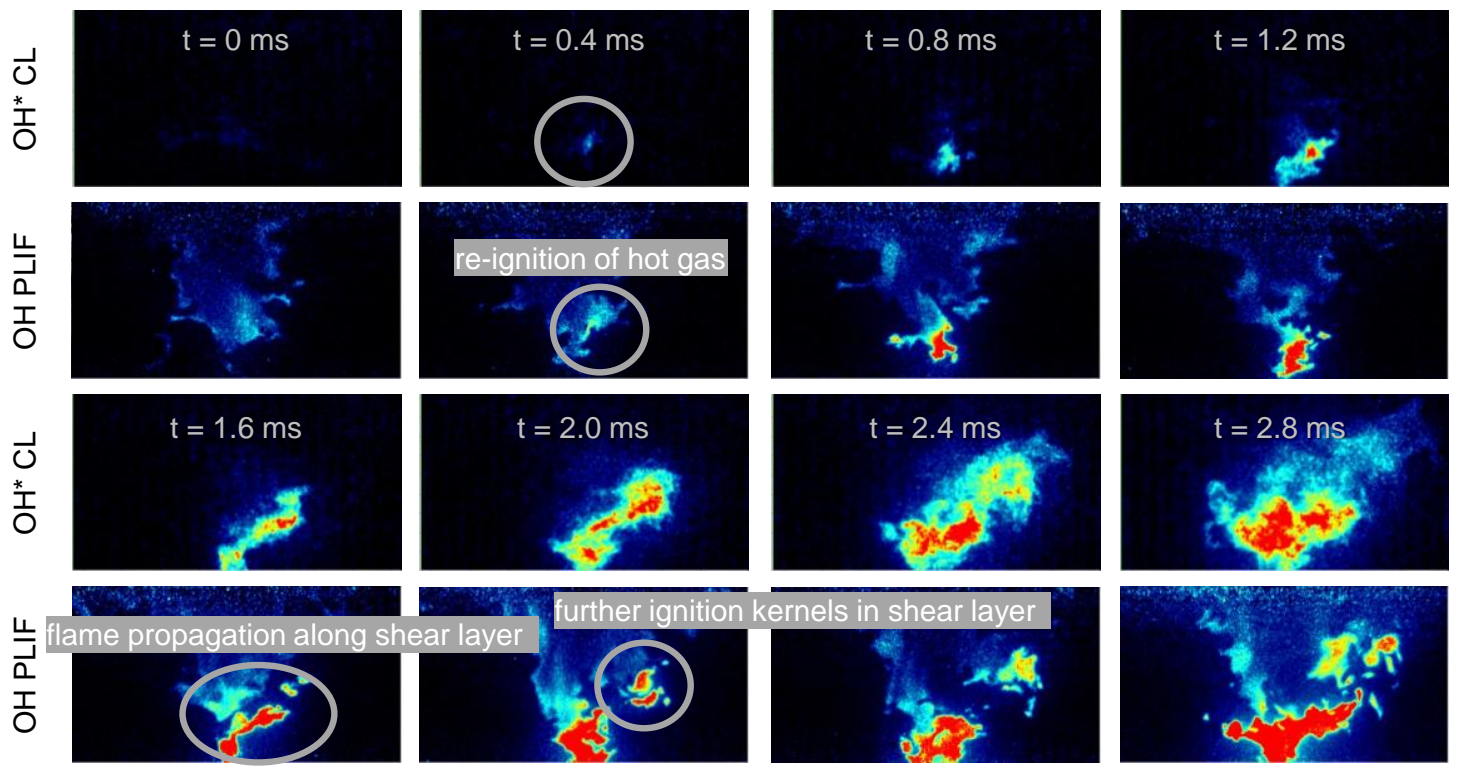

Figure 8. Image sequence of $\mathrm{OH} * \mathrm{CL}$ and $\mathrm{OH}$ PLIF during the flame re-ignition in an intermittent state close to the lean blow-out limit. For a better overview, only every fourth image frame is shown, corresponding to a time between the images of $0.4 \mathrm{~ms}$.

In the first frame of the image sequence at $\mathrm{t}=0 \mathrm{~ms}$, no $\mathrm{OH}^{*} \mathrm{CL}$ signal is visible, indicating the absence of flame reactions within the combustion chamber. However, the OH PLIF image at the same time reveals hot, OH containing gas in the inner recirculation zone. As discussed above, the conditionally averaged flow field for the extinguished state showed large regions of negative axial velocities in the IRZ, probably leading to the transport of still hot gas upstream towards the inlet plane. Whether the OH PLIF signal corresponds to weak chemical reactions or just to high temperatures still occurring in the IRZ cannot be determined with absolute certainty. However, the low OH PLIF signal llevel and the absence of an $\mathrm{OH}^{*} \mathrm{CL}$ signal leads to the conclusion that the flame is completely extinguished. At $\mathrm{t}=0.4 \mathrm{~ms}$, a small flame fragment is visible in the $\mathrm{OH}^{*} \mathrm{CL}$ image, corresponding to a re-ignition event. In the OH PLIF frame, an increase of signal can also be observed on the r.h.s. of the image at the interface of the inflow and the IRZ. This flame fragment subsequently growths in axial and radial direction. At $t=1.2 \mathrm{~ms}$, the upstream edge of the flame fragment has propagated into the inner nozzle, and subsequently at $t=2.0 \mathrm{~ms}$ a reaction can be seen along the inner shear layer on the r.h.s. of the combustor in the $\mathrm{OH}^{*} \mathrm{CL}$ frame, probably due to flame propagation along the ISL. During that time, no continuous OH layer is visible in the OH PLIF. This however could be an out-of-plane effect, i.e. reactions occurring outside the measurement plane. At $t=2.0 \mathrm{~ms}$, further flame fragments (either auto-ignition, or transport of reacting fluid from outside the measurement plane) can be observed in the OH PLIF frame. Shortly afterwards, reactions can also be observed on the 1.h.s. of the combustor, and a "stable" flame is re-established, which will eventually extinguish again after some hundred microseconds.

\section{Conclusions and Outlook}

A dual swirl gas turbine model combustor was setup for pre-vaporized liquid fuel flames and studied using highspeed laser diagnostics. Close to the lean blow-out limit (LBO) the flame exhibited an intermittend state, where it frequently extinguished and, after a short time period of several ten microseconds, re-ignited again. Both the flame extinction and re-ignition events occurred on a timescale on the order of a few milliseconds. The duration of the reignition event however was approximately half as long as that of the extinction event. The time between the individual extinction / re-ignition events was on the order of several hundred milliseconds. After the flame reignited, an increased $\mathrm{OH}^{*} \mathrm{CL}$ signal level about twice the level of the long-time average was observed. This was attributed to the reaction of fuel that accumulated in the combustion chamber during the extinguished state, leading to increased reactions and a temporary increased global equivalence ratio within the combustion chamber.

Immediately before a global extinction event, local flame extinction at the flame root and downstream of the flame root were observed. The extinguished regions grew in number and size, until global extincition was observed. A comparison of the conditionally averaged flow-fields of the reacting and extinguished states revealed that the 
magnitude of the backflow increased when the flame was extinguished, while the velocity magnitude of the inflow decreased. Hot, $\mathrm{OH}$ containing gas remained present in the inner recirculation zone while the flame was extinguisehd. Isolated flame gragments occured in the inner shear layer, and subsequent flame propagation in combination with further "ignition events" led to the establishment of a "stable" flame.

\section{Acknowledgements}

Redjem Hadef, Jasper Grohmann and Yawei Gao are gratefully acknowledged for their support in setting up the experiment.

\section{References}

[1] IATA, Fact Sheet - Climate Change \& CORSIA (2018).

[2] T. Edwards, C. Moses, F. Dryer Evaluation of Combustion Performance of Alternative Aviation Fuels, 46th AIAA/ASME/SAE/ASEE Joint Propulsion Conference \& Exhibit (2010).

[3] J. Grohmann, W. O'Loughlin, W. Meier, M. Aigner Comparison of the Combustion Characteristics of Liquid Single-Component Fuels in a Gas Turbine Model Combustor, Proceedings of the ASME Turbo Expo (2016).

[4] J. Grohmann, B. Rauch, T. Kathrotia, W. Meier, M. Aigner Investigation of differences in lean blowout of liquid single-component fuels in a gas turbine model combustor, 52nd AIAA/SAE/ASEE Joint Propulsion Conference (2016).

[5] J. Grohmann, W. Meier, M. Aigner Gas Turbine Model Combustor Emissions of Liquid Single-Component Fuels, Proceedings of the ASME Turbo Expo (2017).

[6] S. Blakey, L. Rye, C. W. Wilson, Aviation gas turbine alternative fuels: A review, Proc. Combust. Inst. 33 (2011) 2863-2885.

[7] J. Grohmann, B. Rauch, T. Kathrotia, W. Meier, M. Aigner, Influence of Single-Component Fuels on GasTurbine Model Combustor Lean Blowout, Journal of Propulsion and Power 34 (2017) 97-107.

[8] N. Rock, I. Chterev, B. Emerson, S. H. Won, J. Seitzman, T. Lieuwen, Liquid Fuel Property Effects on Lean Blowout in an Aircraft Relevant Combustor, J. Eng. Gas Turbines Power 141 (2019) 071005-071005-13.

[9] S. H. Won, N. Rock, S. J. Lim, S. Nates, D. Carpenter, B. Emerson, T. Lieuwen, T. Edwards, F. L. Dryer, Preferential vaporization impacts on lean blow-out of liquid fueled combustors, Combust. Flame 205 (2019) 295304.

[10] M. Stöhr, I. Boxx, C. Carter, W. Meier, Dynamics of lean blowout of a swirl-stabilized flame in a gas turbine model combustor, Proc. Combust. Inst. 33 (2011) 2953-2960.

[11] A. J. Morales, I. M. Lasky, M. K. Geikie, C. A. Engelmann, K. A. Ahmed, Mechanisms of flame extinction and lean blowout of bluff body stabilized flames, Combust. Flame 203 (2019) 31-45.

[12] N. Rock, B. L. Emerson, J. Seitzman, T. Lieuwen Dynamics of Spray Flames under Near-Lean Blowoff Conditions, AIAA Scitech 2019 Forum (2019).

[13] A. Mukhopadhyay, R. R. Chaudhari, T. Paul, S. Sen, A. Ray, Lean Blow-Out Prediction in Gas Turbine Combustors Using Symbolic Time Series Analysis, Journal of Propulsion and Power 29 (2013) 950-960.

[14] S. Sarkar, A. Ray, A. Mukhopadhyay, S. Sen, Dynamic Data-Driven Prediction of Lean Blowout in a SwirlStabilized Combustor, International Journal of Spray and Combustion Dynamics 7 (2015) 209-241.

[15] A. Kaluri, P. Malte, I. Novosselov, Real-time prediction of lean blowout using chemical reactor network, Fuel 234 (2018) 797-808.

[16] A. Ateshkadi, V. G. McDonell, G. S. Samuelsen, Lean blowout model for a spray-fired swirl-stabilized combustor, Proc. Combust. Inst. 28 (2000) 1281-1288.

[17] M. R. Johnson, D. Littlejohn, W. A. Nazeer, K. O. Smith, R. K. Cheng, A comparison of the flowfields and emissions of high-swirl injectors and low-swirl injectors for lean premixed gas turbines, Proc. Combust. Inst. 30 (2005) 2867-2874.

[18] K. Kumaran, U. S. P. Shet, Effect of swirl on lean flame limits of pilot-stabilized open premixed turbulent flames, Combust. Flame 151 (2007) 391-395.

[19] T. M. Muruganandam, S. Nair, D. Scarborough, Y. Neumeier, J. Jagoda, T. Lieuwen, J. Seitzman, B. Zinn, Active Control of Lean Blowout for Turbine Engine Combustors, Journal of Propulsion and Power 21 (2005) 807814.

[20] C. M. Arndt, A. M. Steinberg, J. Böhnke, R. Hadef, W. Meier High Speed Imaging of Flame Structure and Dynamic Processes in Swirl Stabilized Prevaporized Liquid Fuel Flames, AIAA Scitech 2019 Forum (2019). 
[21] C. M. Arndt, M. Severin, C. Dem, M. Stohr, A. M. Steinberg, W. Meier, Experimental analysis of thermoacoustic instabilities in a generic gas turbine combustor by phase-correlated PIV, chemiluminescence, and laser Raman scattering measurements, Exp. Fluids 56 (2015) 69.

[22] W. Meier, C. Dem, C. M. Arndt, Mixing and reaction progress in a confined swirl flame undergoing thermoacoustic oscillations studied with laser Raman scattering, Exp. Therm. Fluid Sci. 73 (2015) 71-78.

[23] C. M. Arndt, M. Stöhr, M. J. Severin, C. Dem, W. Meier Influence of air staging on the dynamics of a precessing vortex core in a dual swirl gas turbine model combustor, 53rd AIAA/SAE/ASEE Joint Propulsion Conference (2017) AIAA 2017-4683.

[24] E. Bärow, R. Koch, H.-J. Bauer Comparison of oscillation modes of spray and gaseous flames, Proceedings of the Eighth Mediterranean Combustion Symposium (2013) EGTSC-26.

[25] C. Kraus, S. Harth, H. Bockhorn, Experimental investigation of combustion instabilities in lean swirlstabilized partially-premixed flames in single- and multiple-burner setup, International Journal of Spray and Combustion Dynamics 8 (2016) 4-26.

[26] C. Kraus, L. Selle, T. Poinsot, C. M. Arndt, H. Bockhorn, Influence of Heat Transfer and Material Temperature on Combustion Instabilities in a Swirl Burner, J. Eng. Gas Turbines Power 139 (2016) 051503.

[27] R. S. Pathania, A. Skiba, J. A. Sidey, E. Mastorakos Blow-off mechanism in a turbulent premixed bluff-body stabilized flame with pre-vaporized fuels, AIAA Scitech 2019 Forum (2019).

[28] P. M. Allison, J. A. Sidey, E. Mastorakos Lean Blowoff Scaling of Swirling, Bluff-Body Stabilized Spray Flames, 56th AIAA Aerospace Sciences Meeting (2018). 